\title{
Renal scar formation after urinary tract infection in children
}

Young Seo Park, MD

Department of Pediatrics, Asan Medical Center, University of Ulsan College of Medicine, Seoul, Korea
Received: 17 May 2012, Accepted: 18 July 2012

Corresponding author: Young Seo Park, MD

Department of Pediatrics, Asan Medical Center, University of Ulsan College of Medicine, 88 Olympic-ro 43-gil, Songpa-gu, Seoul 138-736, Korea

Tel: +82-2-3010-3376, Fax: +82-2-473-3725

E-mail: yspark@amc.seoul.kr

Copyright (C) 2012 by The Korean Pediatric Society
Urinary tract infection (UTI) is a common bacterial illness in children. Acute pyelonephritis in children may lead to renal scarring with the risk of later hypertension, preeclampsia during pregnancy, proteinuria, and renal insufficiency. Until now, vesicoureteral reflux (VUR) has been considered the most important risk factor for post-UTI renal scar formation in children. VUR predisposes children with UTI to pyelonephritis, and both are associated with renal scarring. However, reflux nephropathy is not always acquired; rather, it reflects refluxassociated congenital dysplastic kidneys. The viewpoint that chronic kidney disease results from renal maldevelopment-associated VUR has led to questioning the utility of any regimen directed at identifying or treating VUR. Despite the recognition that underlying renal anomalies may be the cause of renal scarring that was previously attributed to infection, the prevention of renal scarring remains the goal of all therapies for childhood UTI. Therefore, children at high risk of renal scar formation after UTI should be treated and investigated until a large clinical study and basic research give us more information.

Key words: Urinary tract infection, Renal scar, Vesico-ureteral reflux, Child

This is an open-access article distributed under the terms of the Creative Commons Attribution Non-Commercial License (http://creativecommons.org/licenses/by$\mathrm{nc} / 3.0 /$ ) which permits unrestricted non-commercial use, distribution, and reproduction in any medium, provided the original work is properly cited.

Urinary tract infection (UTI) is a common bacterial illness in children. Acute pyelonephritis (APN) in children may lead to renal scarring, which results from a complex interactions between host and bacterial factors, leading to acute renal parenchymal damage and subsequent permanent damage ${ }^{1)}$. Extensive scarring may progress to further renal injury with subsequent hypertension, decreased renal function, proteinuria, and sometimes end-stage renal disease ${ }^{1)}$.

Permanent renal scarring has been observed after UTI in 15 to $60 \%$ of affected children ${ }^{2,3)}$. These wide variations may be due to different sample sizes and the inclusion of heterogenous patient populations with variations in age, gender distribution, diagnostic criteria for UTI, reflux grade, comorbid urological anomalies, and genetic background. We recently reported that $17 \%$ of infants with APN confirmed using technetium Tc 99m dimercaptosuccinic acid (DMSA) renal scintigraphy had permanent renal scarring on follow-up DMSA renal scintigraphy, a relatively lower incidence than previously reported ${ }^{4)}$.

Risk factors for renal scar formation in children after UTI have been reported to include: age at presentation; gender; recurrent infection; peak fever; treatment delay; presence of vesicoureteral reflux (VUR); laboratory indices of inflammation such as total white blood cell (WBC) count, erythrocyte sedimentation rate, and C-reactive 
protein (CRP) level; bacterial virulence; host defense factors; and genetic subsceptibility ${ }^{4-9)}$. These factors have varied among studies due to difficulties in the accurate diagnosis of UTI in young children, especially infants, because sterile urine collection is difficult and symptoms of UTI are nonspecific. Thus, many studies may have enrolled patients without UTI. Moreover, although DMSA renal scintigraphy is considered accurate for the diagnosis of APN because of its high sensitivity and specificity in detecting renal inflammation, this method has a limited ability to differentiate between acute inflammation and renal scarring.

Many reports have investigated children over a broad age range. Renal scars, which may have developed in older children after previous unrecognized UTIs, cannot be differentiated from acute photon defects on DMSA renal scintigraphy. Finally, the relationship between VUR and renal scar formation cannot be accurately determined in older children because VUR may improve or resolve over time. Therefore, older children without VUR at the time of investigation may have previously had VUR.

To avoid the limitations of these earlier studies, we prospectively studied the risk factors for renal scar formation after first APN, as confirmed on DMSA renal scintigraphy, in children $<1$ year of age without urological abnormalities other than VUR. We evaluated possible risk factors including gender, peak fever, duration of fever before and after treatment with antibiotics, WBC count, CRP concentration, presence of VUR, and reflux grade ${ }^{4)}$.

The results were as follows. The rate of scar formation was significantly higher in infants with VUR than in those without (39.4\% vs. $7.5 \%$; odds ratio [OR], 9.433; 95\% confidence interval [CI], 4.09 to $21.75 ; P<0.001)$ and in renal units with VUR than in those without (39.4\% vs. $8.2 \%$; OR, 7.237 ; $95 \%$ CI, 3.51 to 14.91 ; $P<0.001)$. The incidence of renal scar formation was significantly correlated with VUR grade (none, $8.2 \%$; grade I, 20\%; grade II, $22.7 \%$; grade III, $40 \%$; grade IV, $70 \%$; and grade V, $55.6 \%$ ). VUR severity was significantly associated with the risk of permanent renal damage. There were no significant differences in gender, peak fever, duration of fever before and after treatment with antibiotics, WBC count, or CRP concentration for renal scar formation. We concluded that the presence of VUR was the only independent risk factor for renal scar formation after APN in infants, and the prevalence of renal scarring was significantly correlated with reflux grade.

We reported another study to assess the impact of VUR on renal scarring following APN by comparing the refluxing renal units with non-refluxing renal units in children with unilateral primary VUR"). This study chose renal units of patients with unilateral VUR as a good model for evaluating the relationship among VUR, UTI, and renal scars because both the refluxing and the nonrefluxing kidney- ureter units are inserted into the same bladder, share the same host defenses and genetic susceptibility, and are subjected to the same bacterial virulence.

The results were as follows. The first DMSA showed renal defects in $34(70.8 \%)$ of 48 of the refluxing renal units and in 13 (27.1\%) of 48 of the nonrefluxing renal units (OR, 6.54; $P<0.01)$. At 6 months after the infection, 23 (47.9\%) of 48 refluxing renal units and 7 (14.6\%) of 48 nonrefluxing renal units had renal scars on DMSA scan (OR, 5.39; $P<0.01)$. We concluded that VUR increases the risk of postpyelonephritic renal scars in children in this study. A metaanalysis demonstrated that children and renal units with VUR were at increased risk for renal scarring compared with those without VUR (OR, 2.8 and 3.8, respectively) $)^{2}$. Many reports also showed a significant correlation between reflux grade and renal scarring frequency, suggesting that VUR increases the risk of renal scar formation after $\mathrm{UTS}^{5,10,11)}$. Therefore, VUR is the most important risk factor for the development of postpyelonephritic renal scars.

However, renal scars have been observed to develop in the absence of VUR. We also observed many infants without VUR in whom permanent renal scarring developed and evaluated the clinical and laboratory variables in infants without VUR if there were any significant risk factors for renal scar formation. No significant differences in clinical and laboratory findings were found between infants with and those without renal scars, and these results may reflect the role of other risk factors such as bacterial virulence, host defense factors, and genetic susceptibility ${ }^{4}$.

The exact pathogenesis of renal scarring following APN is not well understood. According to Roberts ${ }^{12}$, the acute inflammatory response that is meant to eradicate the invading bacteria is also responsible for early renal parenchymal damage and subsequent scarring. This process is an inflammatory response that features chemotaxis, phagocytosis, the release of lysosomal enzymes and superoxides, the production of peroxide and hydroxyl radicals, tubular ischemia, and reperfusion injury. The fibrosis that follows is initiated mainly by macrophages.

The pathogenesis of proteinuria in reflux nephropathy is also not well understood, and it is variably attributed to immunological injury, macromolecular trapping and mesangial dysfunction, vascular alterations and hypertension, and glomerular hyperfiltration ${ }^{13}$. Of these explanations, the one that is most widely accepted is that glomerular hyperfiltration in remnant nephrons result in modifications of selective permeability to macromolecules such as albumin and the progression of renal disease. The histological hallmark in such patients is hypertrophy of surviving nephrons with focal segmental glomerulosclerosis.

Hypertension occurs in 10 to $30 \%$ of children and young adults 
with renal scarring, and it may take up to 8 years to develop ${ }^{14)}$. The exact cause of hypertension due to renal scarring is not known, but it is believed to be due to segmental ischemia with increased renin secretion, and it is not dependent on scarring severity. However, the belief that infection and VUR are the cause of upper tract parenchymal damage is undergoing critical review. Increasing knowledge shows that reflux nephropathy is not always acquired but that it rather reflects reflux-associated damage related to congenital dysplastic kidneys ${ }^{15)}$. In fact, it may be considered part of the congenital abnormality of the kidney and the urinary tract syndrome ${ }^{16)}$.

Because of the importance of VUR in UTI, most pediatric societies recommended routine voiding cystourethrograpy (VCUG) for all children with a first febrile UTI prior to 2006. The likelihood of identifying VUR using such a strategy is 20 to $40 \%$. Most of the VUR diagnosed are low grade. Two recent studies of children with low grade VUR showed no significant differences in risk for UTI between antibiotic prophylaxis and no treatment ${ }^{17,18}$. The fact that antibiotic prophylaxis is not necessary in cases of low-grade VUR is likely going to affect current guidelines.

Regarding the utilization of VCUG in the evaluation of all children with their first febrile UTI, current practice guidelines focus on performing selected investigations in high-risk children. This group of children has an increased risk of having an abnormal urinary tract that warrants investigation. By targeting investigations to specific children, clinicians can avoid many unnecessary and invasive investigations ${ }^{19)}$. This statement is in accordance with the guideline published in August 2007 by the National Institute of Health and Clinical Excellence ${ }^{20)}$.

High-risk children include: those with an increased levels of procalcitonin, which has high sensitivity in identifying children with severe reflux; and those with high fever who are younger than 6 months of age, recurrent UTI, clinical signs such as poor urinary stream or palpable kidneys, infection with atypical organisms, bacteremia or septicemia, prolonged clinical course with failure to respond fully to antibiotic treatment within 48 to 72 hours; unusual clinical presentations such as an older boy, or with a known abnormality on antenatal ultrasound screening of the urinary tract. Such high-risk children should undergo ultrasonography and VCUG with their first episode of UTI. According to the Swedish state of the art conference, in children $>2$ years of age, DMSA scintigraphy alone or with ultrasonography was suggested as the way to identifying at-risk patients ${ }^{211}$. A voiding cystourethrogram is performed only if the DMSA scintigraphy is abnormal. Therefore, the traditional recommendation to perform the VCUG at 3 to 6 weeks after the diagnosis of UTI should be reconsidered. Further, the recommendation to perform VCUG, when indicated, early in the course of infection should be reconsidered as the VUR detection rate does not increase over time in the study.

The 2011 American Academy of Pediatrics (AAP) guideline most dramatically differs from the 1999 guideline in that VCUG should not be routinely performed after a first febrile $\mathrm{UTI}^{22}$. The main reason for this change is the accumulation of evidence casting doubt on the benefit of making a diagnosis of VUR. The AAP recommendation to perform a VCUG after the second UTI is based on the increasing likelihood of detecting higher grades of refluxin children with recurrent UTIs and the belief that detecting grade V reflux is beneficial. However, the guideline appropriately recognizes that grade $\mathrm{V}$ reflux is rare and that the benefits of diagnosing it are still in some doubt. Therefore, the guideline suggests that parent preferences be considered in making these imaging decisions.

Despite the recognition that underlying renal anomalies may be the cause of renal scarring that was previously attributed to infection, the prevention of renal scarring remains the goal of all therapies for childhood UTI. Although new data have questioned previous dogma of urinary tract imaging, parental therapy of pyelonephritis, and the use of antimicrobial prophylaxis, the clinician must be vigilant in recognizing children at risk of complications from UTI. High-risk children such as those $<6$ months of age with high fever, those with abnormal genitourinary anatomy, and those with a septic presentation at any age should be treated and investigated aggressively. The recognition of antenatal urinary abnormalities, improved imaging strategies, better understanding of the molecular and cellular pathophysiology of renal scarring, and the development of new pharmacogenomically derived individualized antimicrobial treatment regimens offers the hope of reducing renal scarring and its complications.

\section{References}

1. Peters C, Rushton HG. Vesicoureteral reflux associated renal damage: congenital reflux nephropathy and acquired renal scarring. J Urol 2010;184:265-73.

2. Faust WC, Diaz M, Pohl HG. Incidence of post-pyelonephritic renal scarring: a meta-analysis of the dimercapto-succinic acid literature. J Urol 2009;181:290-7.

3. Shaikh N, Ewing AL, Bhatnagar S, Hoberman A. Risk of renal scarring in children with a first urinary tract infection: a systematic review. Pediatrics 2010;126:1084-91.

4. Lee YJ, Lee JH, Park YS. Risk factors for renal scar formation in infants with first episode of acute pyelonephritis: a prospective clinical study. J Urol 2012;187:1032-6.

5. Orellana P, Baquedano P, Rangarajan V, Zhao JH, Eng ND, Fettich $\mathrm{J}$, et al. Relationship between acute pyelonephritis, renal scarring, and 
vesicoureteral reflux: results of a coordinated research project. Pediatr Nephrol 2004;19:1122-6.

6. Pecile P, Miorin E, Romanello C, Vidal E, Contardo M, Valent F, et al. Age-related renal parenchymal lesions in children with first febrile urinary tract infections. Pediatrics 2009;124:23-9.

7. Jahnukainen T, Chen M, Celsi G. Mechanisms of renal damage owing to infection. Pediatr Nephrol 2005;20:1043-53.

8. Wullt B, Bergsten G, Fischer H, Godaly G, Karpman D, Leijonhufvud I, et al. The host response to urinary tract infection. Infect Dis Clin North Am 2003;17:279-301.

9. Lee JH, Son CH, Lee MS, Park YS. Vesicoureteral reflux increases the risk of renal scars: a study of unilateral reflux. Pediatr Nephrol 2006;21:12814.

10. Soylu A, Demir BK, Turkmen M, Bekem O, Saygi M, Cakmakci H, et al. Predictors of renal scar in children with urinary infection and vesicoureteral reflux. Pediatr Nephrol 2008;23:2227-32.

11. Zaffanello M, Cataldi L, Brugnara M, Franchini M, Bruno C, Fanos V. Hidden high-grade vesicoureteral reflux is the main risk factor for chronic renal damage in children under the age of two years with first urinary tract infection. Scand J Urol Nephrol 2009;43:494-500.

12. Roberts JA. Etiology and pathophysiology of pyelonephritis. Am J Kidney Dis 1991;17:1-9.

13. Cotran RS. Nephrology Forum. Glomerulosclerosis in reflux nephropathy. Kidney Int 1982;21:528-34.

14. Smellie JM, Prescod NP, Shaw PJ, Risdon RA, Bryant TN. Childhood reflux and urinary infection: a follow-up of 10-41 years in 226 adults.
Pediatr Nephrol 1998;12:727-36.

15. Williams G, Fletcher JT, Alexander SI, Craig JC. Vesicoureteral reflux. J Am Soc Nephrol 2008;19:847-62.

16. Ichikawa I, Kuwayama F, Pope JC 4th, Stephens FD, Miyazaki Y. Paradigm shift from classic anatomic theories to contemporary cell biological views of CAKUT. Kidney Int 2002;61:889-98.

17. Garin EH, Olavarria F, Garcia Nieto V, Valenciano B, Campos A, Young L. Clinical significance of primary vesicoureteral reflux and urinary antibiotic prophylaxis after acute pyelonephritis: a multicenter, randomized, controlled study. Pediatrics 2006;117:626-32.

18. Roussey-Kesler G, Gadjos V, Idres N, Horen B, Ichay L, Leclair MD, et al. Antibiotic prophylaxis for the prevention of recurrent urinary tract infection in children with low grade vesicoureteral reflux: results from a prospective randomized study. J Urol 2008;179:674-9.

19. Marks SD, Gordon I, Tullus K. Imaging in childhood urinary tract infections: time to reduce investigations. Pediatr Nephrol 2008;23:9-17.

20. National Institute for health and Clinical Excellence. Urinary tract infection in children (CG54) [Internet]. London: National Institute for health and Clinical Excellence; c2012 [cited 2012 May 17]. Available from: http://www.nice.org.uk/CG054.

21. Jodal U, Lindberg U. Guidelines for management of children with urinary tract infection and vesico-ureteric reflux: recommendations from a Swedish state-of-the-art conference. Swedish Medical Research Council. Acta Paediatr Suppl 1999;88:87-9.

22. Newman TB. The new American Academy of Pediatrics urinary tract infection guideline. Pediatrics 2011;128:572-5. 